\title{
PENERAPAN LANGKAH-LANGKAH MENUJU TERCAPAINYA KESELAMATAN PASIEN DALAM MEMBERIKAN ASUHAN KEPERAWATAN
}

\author{
Elisa Claudia Simanjuntak / 181101114 \\ elclaudia02@gmail.com
}

\begin{abstract}
ABSTRAK
Latar Belakang : Keselamatan Pasien adalah satu hal yang sangat penting untuk dijadikan dasar dalam pemberian asuhan. Menjamin keselamatan pasien adalah tugas rumah sakit untuk memberikan rasa aman kepada pasien selama menjalani perawatan. Keselamatan pasien sudah diatur dalam PERMENKES No. 1691 Tahun 2011.

Tujuan : Tujuan penulisan kajian ini adalah untuk mengetahui langkah-langkah keselamatan pasien di rumah sakit selama pemberian asuhan keperawatan.

Metode : Metode yang digunakan dalam kajian ini adalah literature review, yaitu dengan cara menganalisis, mengeksplorasi serta mengkaji bebas jurnal dan buku teks yang membahas tentang penerapan langkah-langkah keselamatan pasien di rumah sakit selama pemberian asuhan keperawatan.

Hasil : Hasil pengkajian menunjukan bahwa langkah-langkah keselamatan pasien dapat berjalan dengan baik apabila tenaga kesehatan mampu bersikap terbuka dalam mengintegrasikan suatu kejadian yang berhubungan dengan keselamatan pasien serta sadar akan pentingnya keselamatan pasien.

Pembahasan : Langkah-langkah keselamatan pasien yang diatur dalam PERMENKES ada tujuh langkah, yaitu membangun kesadaran akan nilai keselamatan pasien, memimpin dan mendukung staf,

mengintegrasikan aktivitas pelaporan risiko, mengembangkan sistem pelaporan, melibatkan dan berkomunikasi dengan pasien, belajar dan berbagi pengalaman tentang keselamatan pasien, serta mencegah cedera melalui implementasi sistem keselamatan pasien.

Kata Kunci : Langkah Keselamatan Pasien, Tenaga Kesehatan, Rumah Sakit.
\end{abstract}




\section{Latar Belakang}

Keselamatan Pasien adalah satu hal yang sangat penting untuk dijadikan dasar dalam memberikan pelayanan.

Dalam memberikan pelayanannya, rumah sakit sebagai sebuah institusi diwajibkan memberikan pelayanan sebagaimana diatur dalam PERMENKES RI No. 1691 Tahun 2011.

Keselamatan pasien adalah proses dimana rumah sakit memberikan rasa aman kepada pasien selama menjalani perawatan. Untuk membantu rumah sakit menjalankan kewajibannya, Menteri Kesehatan membentuk suatu komite nasional dimana tugasnya adalah memberikan masukan dan pertimbangan dalam rangka menyusun kebijakan nasional dan peraturan keselamatan pasien di rumah sakit.

Tujuh langkah menuju

keselamatan pasien merupakan acuan rumah sakit dalam melaksanakan program keselamatan pasien. Tujuh langkah tersebut adalah membangun kesadaran akan nilai keselamatan pasien, memimpin dan mendukung staf, mengintegrasikan aktivitas pelaporan risiko, mengembangkan sistem pelaporan, melibatkan dan berkomunikasi dengan pasien, belajar dan berbagi pengalaman tentang keselamatan pasien, serta mencegah cedera melalui implementasi sistem keselamatan pasien.

\section{Tujuan}

Untuk mengetahui langkah-langkah keselamatan pasien di rumah sakit selama pemberian asuhan keperawatan.

\section{Metode}

Metode yang digunakan dalam kajian ini adalah literature review, yaitu dengan cara menganalisis, mengeksplorasi serta mengkaji bebas jurnal dan buku teks yang membahas tentang langkah-langkah keselamatan pasien di rumah sakit. Referensi berupa jurnal dan buku teks yang digunakan adalah sebanyak 14. Jurnal yang digunakan sebagai referensi dalam tulisan ini diterbitkan dalam kurun waktu 10 tahun terakhir.

\section{Hasil}

Hasil pengkajian menunjukan bahwa langkah-langkah keselamatan pasien dapat berjalan dengan baik apabila tenaga kesehatan mampu bersikap terbuka dan sadar akan keselamatan pasien. Keselamatan pasien 
dilakukan untuk memberikan rasa aman kepada pasien di rumah sakit.

\section{Pembahasan}

Menurut Pasal 43 UU

Kesehatan No. 36 tahun 2009 yang dimaksud dengan keselamatan pasien (patient safety) adalah proses dalam suatu rumah sakit yang memberikan pelayanan kepada pasien secara aman termasuk didalamnya pengkajian mengenai resiko, identifikasi, manajemen resiko terhadap pasien, pelaporan dan analisis insiden, kemampuan untuk belajar dan menindaklanjuti insiden, dan menerapkan solusi untuk mengurangi serta meminimalisir timbulnya risiko.

Selama masa perawatan, pasien memiliki hak untuk memperoleh pelayanan yang bermutu sesuai dengan standar agar tehindar dari berbagai kerugian. Salah satu hal yang harus dilakukan adalah menerapkan langkahlangkah keselamatan pasien. Langkahlangkah keselamatan pasien diuraikan menjadi:

1. Membangun kesadaran akan nilai keselamatan pasien.

Hal ini perlu dilakukan untuk menghindari atau mengurangi kesalahan dalam menanggapi suatu kejadian yang berhubungan dengan keselamatan pasien. Untuk membangun kesadaran akan nilai keselamatan pasien, rumah sakit atau tenaga kesehatan yang ada di dalamnya harus terbuka dan adil apabila terjadi suatu insiden.

\section{Pimpin dan dukung staf}

Untuk upaya mendemonstrasikan keselamatan pasien, pimpinan harus menyisihkan waktu satu jam dalam satu minggu untuk mengunjungi unit kerja yang berbeda untuk membahas keselamatan pasien dan tata kelola klinis dengan staf.

3. Integrasikan aktivitas pengelolaan resiko

Mengintegrasikan pengelolaan resiko dilakukan untuk memberikan pembelajaran bagi setiap unit yang berada di rumah sakit. Pengelolaan resiko dapat dilakukan dengan cara mengidentifikasi risiko masing-masing, melakukan penilaian risiko dan melaporkannya kepada KMKP (Komite Mutu dan Keselamatan Pasien).

4. Kembangkan sistem pelaporan

Hal yang sangat penting dalam menjalankan langkah ini adalah sifat terbuka. Rumah sakit atau tenaga kesehatan harus mau terbuka mengenai insiden yang terjadi dengan cara tidak menutupinya. Dalam sistem pelaporan 
ini, tenaga kesehatan juga tidak boleh saling menyalahkan agar sistem pelaporan ini dapat berjalan dengan baik.

5. Libatkan dan berkomunikasi dengan pasien

Pada langkah ini, tenaga kesehatan harus mampu berkomunikasi secara terbuka dengan pasien mengenai insiden yang terjadi. Sikap yang terbuka dapat membantu pasien dalam menghadapi efek akibat kesalahan yang terjadi.

6. Belajar dan berbagi pengalaman tentang keselamatan pasien

Hal ini dapat dilakukan dengan cara berdiskusi antar tenaga kesehatan pada saat melakukan rapat.

7. Cegah cedera melalui implementasi sistem keselamatan pasien

\section{Penutup}

Keselamatan pasien merupakan suatu proses yang harus dilakukan oleh tenaga kesehatan di rumah sakit untuk memberikan rasa aman kepada pasien selama menjalani proses perawatan. Dalam menjalankan keselamatan pasien, ada langkah-langkah yang diatur dalam PERMENKES No. 1691 Tahun 2011 yang meliputi membangun kesadaran akan nilai keselamatan pasien, memimpin dan mendukung staf, mengintegrasikan aktivitas pelaporan risiko, mengembangkan sistem pelaporan, melibatkan dan berkomunikasi dengan pasien, belajar dan berbagi pengalaman tentang keselamatan pasien, serta mencegah cedera melalui implementasi sistem keselamatan pasien.

\section{Referensi}

Azrul, A. (1996). Menuju Pelayanan Kesehatan Yang Bermutu. Jakarta : Salemba Medika.

Basabih, Masyitoh. (2017).Perlukah Keselamatan Pasien Menjadi Indikator Kinerja RS. BLU ?. Jurnal Administrasi Rumah Sakit Indonesia. 3(2): 150-157.

Darliana, D. (2016). Hubungan Pengetahuan Perawat dengan Upaya Penerapan Patient Safety di Ruang Rawat Inap RSUD Dr. Zainoel Abidin Banda Aceh. Idea Nursing Journal. 7(1): 62-63.

Firawati. (2012). Pelaksanaan Program Keselamatan Pasien di RSUD Solok. Jurnal Kesehatan Masyarakat. 6(2): 7477. 
Ida, Wulandari. (2018). Strategi

Peningkatan Kualitas Pelayanan

Rumah Sakit Berdasarkan Indikator

Mutu Keselamatan Pasien: Studi Pada

Rumah Sakit Umum Hidayaj Boyolali.

Surakarta: FPUM.

Ismainar, Hetty. (2015). Keselmatan

Pasien di Rumah Sakit. Yogyakarta:

Deepublish.

Kemenkes RI. (2011). Peraturan

Menteri Kesehatan Republik Indonesia Nomor1691/MENKES/PER/VIII/2011

tentang Keselamatan Pasien Rumah

Sakit. Jakarta: Depkes RI.

Nugroho, Sri H.P., Sujianto,U. (2014).

Supervisi Kepala Ruang Model Proctor

Untuk Meningkatkan Pelaksanaan

Keselamatan Pasien. Jurnal

Keperawatan Indonesia. 20(1): 56-64.

Rachmawati, Alifa R., dkk. (2017). Analisis Pelaksanaan Tujuh Langkah Menuju Keselamatan Pasien di Rumah Sakit Islam Sultan Agung Semarang. Jurnal Kesehatan Masyarakat. 5(1): 1-7.

Rivai, F., Sidin, A.I. (2016). Faktor Yang berhubungan dengan implementasi keselamatan pasien di
RSUD Ajjapponnge Soppeng Tahun 2015. Jurnal Kebijakan Kesehatan Indonesia. (5): 152-157.

Simamora, R. H. (2019). The infiuence of Training Handover Based SBAR Communication for Improving Patients Safety. Indian Journal of Public Health Research \& Development.

Utarini, A. \& Djasri, H. (2012). Keselamatan Pasien dan Mutu Pelayanan Kesehatan. Jurnal Manajemen Pelayanan Kesehatan. 159160.

Yulia, S., dkk. (2012). Peningkatan Pemahaman Perawat Pelaksana dalam Penerapan Keselamatan Pasien Melalui Pelatihan Keselamatan Kerja. Jurnal Keperawatan. 15(3): 185-192.

Yulidar, E. \& Nasution, A. (2019). Analisi Faktor-Faktor yang Mempengaruhi Perilaku Perawat Dalam Rangka Penerapan Patient Safety di Rawat Inap RS. Royal Prima Jambi Tahun 2018. Scientia Journal. 8(1): 370-371. 